\title{
Explorando Uma Lista De Transmissão Para Refletir Sobre O Conhecimento Matemático Para O Ensino De Análise Combinatória
}

\section{Exploring A Broadcast List To Reflect On Mathematical Knowledge For Teaching In Combinatory Analysis}

\author{
Elion Souza da Silva* \\ Instituto Federal de Educação, Ciência e Tecnologia do Ceará - (IFCE) \\ Fabiana Chagas de Andrade ** \\ Centro Federal de Educação Tecnológica do Rio de Janeiro - (CEFET/RJ). \\ Jefferson Araújo dos Santos ${ }^{* * *}$ \\ FIRJAN - (SESI/RJ)
}

\begin{abstract}
Resumo
O presente texto versa sobre o ensino de análise combinatória na educação básica, o qual, de acordo com a literatura de pesquisa em Educação Matemática, é geralmente de difícil compreensão por parte dos alunos (MOREIRA, ALVES, MAGINA, 2013) e um tema relevante para a formação de professores de matemática (BORBA, 2010). Buscamos refletir e discutir os resultados de uma atividade formativa proposta a professores de matemática do Ensino Médio. À luz das noções de Conhecimento Matemático para o Ensino (BALL, THAMES, PHELPS, 2008) e de Conhecimento Pedagógico do Conteúdo (SHULMAN, 1986), delineamos um percurso metodológico de cunho qualitativo, que consistiu no envio de um problema disparador - O Problema dos Diferentes Caminhos (ANDREESCU, FENG, 2013; SILVA, 2017) - a diferentes professores de matemática, através de uma lista de transmissão do aplicativo Whatsapp. Os sujeitos deveriam refletir sobre estratégias de resolução para os alunos em sala de aula. Assim, nosso objetivo foi analisar essas resoluções e discutir suas condutas segundo aspectos conceituais, didáticos e pedagógicos. A partir desse cenário, constatamos que os professores mobilizaram os diferentes aspectos do Conhecimento Matemático para o Ensino, descritos e categorizados por Ball, Thames e Phelps (2008). Por fim, ao simular a resolução do referido problema para os alunos, constatamos que os professores também puderam redimensionar (e refletir sobre) seus saberes, evidenciando que os mesmos aprendem e teorizam durante a sua prática.
\end{abstract}

Palavras-chave: Conhecimento Matemático Para o Ensino; Conhecimento Pedagógico do Conteúdo; Formação de Professores; Ensino de Análise Combinatória

\footnotetext{
* Doutorando em Ensino de Matemática - UFRJ. Mestre em Matemática - UECE. Docente do IFCE, Iguatu, CE, Brasil. E-mail: elionsouza@ifce.edu.br

** Doutoranda em Ensino de Matemática - UFRJ. Mestre em Matemática - Unirio. Docente do CEFET-RJ, Itaguaí, RJ, Brasil. E-mail: Fabiana.andrade@cefet-rj.br

*** Mestrando em Ensino de Matemática - UFRJ. Docente na FIRJAN (SESI/RJ), Nova Iguaçu, RJ, Brasil. E-mail: jeffaraujo30@yahoo.com.br
} 


\begin{abstract}
This study focuses on mathematical knowledge for combinatorics teaching in basic education. According to the research literature in Mathematics Education, this topic is generally difficult to be understood by students (MOREIRA, ALVES, MAGINA, 2013) and a relevant topic for the mathematics teacher education (BORBA, 2010). In the light of the notions of Mathematical Knowledge for Teaching (BALL, THAMES, PHELPS, 2008) and Pedagogical Content Knowledge (SHULMAN, 1986), we outline a methodological itinerary of qualitative character, which consisted of sending a triggering problem - The Different Ways Problem (ANDREESCU, FENG, 2013, SILVA, 2017) - to different mathematics teachers through a broadcast list of the WhatsApp application, inviting them to reflect on resolution strategies for students in the classroom. Thus, our objective was to analyze these resolutions and discuss their knowledge, according to conceptual, didactic and pedagogical aspects. From this point of view, we verified that the teachers mobilized the different aspects of Mathematical Knowledge for Teaching. Finally, in simulating the resolution of this problem for the students, we found that the teachers were also able to resize (and reflect on) their knowledge, evidencing that they learn and theorize during their practice.
\end{abstract}

Keywords: Mathematical Knowledge for Teaching; Pedagogical Content Knowledge; Teacher Education; Combinatorics Teaching

\title{
1 Introdução
}

Refletir sobre a própria prática de ensino é um exercício imprescindível na busca do professor por uma melhor atuação em sala de aula, em prol da aprendizagem de seus alunos. Uma atitude reflexiva, de acordo com Geraldi, Messias e Guerra (1998), inspiradas em Zeichner (1995), implica "uma consideração cuidadosa e ativa daquilo em que se acredita ou se pratica, à luz dos motivos que o justificam e das consequências que daí resultam" (p. 238). Partindo dessa premissa, elaboramos uma atividade para um grupo de professores de matemática que atuam no ensino médio, na intenção de fomentar ricas discussões sobre combinatória, mobilizando e, potencialmente, (re)significando seu conhecimento matemático para o ensino (BALL, THAMES, PHELPS, 2008), em seus vários aspectos, na perene busca por olhar a matemática elementar a partir de um ponto de vista superior, no sentido de Klein (2010). Nosso objetivo fulcral foi tentar compreender as complexidade e especificidades dos saberes mobilizados por professores da educação básica no ensino desse conteúdo. As ideias que discutimos aqui foram parte de uma atividade proposta pelos professores responsáveis pela disciplina Saberes Docentes e Formação de Professores de Matemática, no Programa de Pósgraduação em Ensino de Matemática (PEMAT) da UFRJ, onde as respostas e reflexões dos professores do Ensino Médio foram discutidas e analisadas.

Em linhas gerais, a nossa atividade consistiu em enviar um problema de Análise Combinatória - O Problema dos Diferentes Caminhos (ANDREESCU, FENG, 2013; SILVA, 
2017) - através de uma Lista de Transmissã $o^{1}$ do Whatsapp. Os contatos dessa lista eram todos professores de matemática do ensino médio de escolas públicas ou privadas. Nossa inspiração metodológica, apesar das muitas particularidades, foi em Biza, Nardi e Zachariades (2007), na perspectiva de explorar simulações de situações que possam surgir no dia-a-dia da prática do professor na sala de aula.

Assim, buscamos provocar reflexões nos professores, para então podermos analisar em seus discursos, aspectos do conhecimento matemático para o ensino, à medida em que os mesmos se envolviam na tarefa do problema proposto.

\section{O Conhecimento Pedagógico Do Conteúdo E O Conhecimento Matemático Para O}

\section{Ensino}

Nosso estudo é conduzido à luz dos referenciais teóricos de Shulman (1986), e sua noção de Conhecimento Pedagógico do Conteúdo, e de Ball, Thames e Phelps (2008), que, trazendo as ideias de Shulman para o campo do ensino de matemática, estabeleceram um construto teórico baseada na prática docente, que chamaram de Conhecimento Matemático para o Ensino $^{2}$. Abaixo, descrevemos cada um deles.

\subsection{Conhecimento Pedagógico Do Conteúdo}

Incomodados com pressupostos de incompetência do corpo docente, na década de 80 , Shulman (1986) e seus colaboradores iniciaram sondagens das complexidades da compreensão e transmissão do conhecimento do conteúdo do professor. Eles investigaram acerca da origem dessa imagem negativa acerca do conhecimento do professor, e identificaram o que ficou denominado como o problema do Paradigma Perdido, que "refere-se a um ponto cego em relação ao conteúdo que agora caracteriza a maioria das pesquisas sobre o ensino (...)." (SHULMAN, 1986, p. 7,8, tradução nossa). A conclusão preliminar era clara: O foco das pesquisas no conhecimento do conteúdo do professor era praticamente inexistente, limitandose a preocupações com questões puramente pedagógicas e sociológicas. A partir dessa identificação, Shulman levanta algumas indagações, como: De onde vêm as explicações dos

\footnotetext{
${ }^{1}$ Em uma lista de transmissão, os participantes recebem a mensagem e o emissor recebe cada resposta individualmente, ou seja, os participantes não leem as respostas uns dos outros e não sabem quem são e nem quantas são as pessoas que receberam a mesma mensagem.

${ }^{2}$ Do original em inglês: Mathematical Knowledge for Teaching (MKT).
} 
professores? Como os professores decidem o que ensinar, como representar isso, como questionar os alunos sobre isso e como lidar com problemas de compreensões equivocadas? Quais são as fontes do conhecimento do professor? O que um professor conhece e quando ele começou a conhecer? Como os novos conhecimentos são adquiridos, o conhecimento antigo ressignificado e ambos combinados para formar uma nova base de conhecimento? Ele percebeu, então, a emergente necessidade de se construir um quadro teórico mais coerente.

Shulman (1986) infere, então, que o professor deve compreender as estruturas do conhecimento do conteúdo que leciona, tanto no aspecto disciplinar, como dentro do contexto pedagógico e acerca do currículo, caracterizando, assim, as três categorias de Shulman para o saber de conteúdo docente: (1) Conhecimento (Disciplinar) do Conteúdo; (2) Conhecimento Pedagógico do Conteúdo e (3) Conhecimento Curricular ${ }^{3}$.

\begin{abstract}
À medida em que começamos a investigar as complexidades da compreensão e da transmissão do conhecimento do conteúdo dos professores, a necessidade de se conceber um quadro teórico mais coerente emergiu rapidamente. Quais são os domínios e categorias de conhecimento de conteúdo e conhecimento pedagógico geral relacionado? Em que formas são os domínios e categorias de conhecimento representados nas mentes dos professores? Quais são as formas mais promissoras para se aumentar a aquisição e o desenvolvimento desse conhecimento? Dado que enxergo isso como uma das questões fulcrais para uma investigação disciplinada sobre a formação dos professores, agora vou passar a uma discussão de alguns modos de pensar sobre um domínio particular - O Conhecimento do Conteúdo no Ensino - e algumas das categorias dentro dele. (...) Sugiro que dividamos o Conhecimento de Conteúdo em três categorias: (a) Conhecimento Disciplinar do Conteúdo, (b) Conhecimento Pedagógico do Conteúdo e (c) Conhecimento Curricular. (SHULMAN, 1986, p. 9, tradução nossa).
\end{abstract}

O Conhecimento (Disciplinar) do Conteúdo se refere ao montante e organização do saber em si na mente do professor. Requer compreender as estruturas sintáticas e substantivas do conteúdo, sendo capaz de dizer não somente que algo é assim, mas também saber explicar porque é assim. Os professores também devem compreender os princípios e as bases da organização, e as regras para estabelecer o que é legítimo para fazer e dizer em determinado campo. Para nós, o caso da matemática, por exemplo, demanda um conhecimento que transcende simplesmente saber realizar cálculos ou resolver equações. Requer compreender substancial e substantivamente os conceitos e as representações dos entes matemáticos.

Esperamos que a compreensão do conteúdo do professor seja pelo menos igual ao de seu colega não licenciado, o especialista no conteúdo. (...) Além disso, esperamos que o professor compreenda por que um determinado tópico é particularmente central para uma disciplina, enquanto outro pode ser um

\footnotetext{
${ }^{3}$ Tradução nossa. Respectivamente, Content Knowledge, Pedagogical Content Knowledge e Curricular Knowledge, no texto original.
} 
pouco mais periférico. Isso será importante em julgamentos pedagógicos subsequentes em relação à ênfase curricular. (SHULMAN, 1986, p. 9, tradução nossa).

O Conhecimento Pedagógico do Conteúdo vai de encontro ao conhecimento do conteúdo em si, na dimensão do conhecimento do conteúdo para o ensino. Sendo assim, Shulman está se referindo ao tipo de conhecimento de conteúdo que dialoga e se mistura com o espectro pedagógico. Ele é, em suma, a compreensão do professor de como ajudar os seus alunos a compreender um conteúdo específico, e inclui o conhecimento de tópicos especiais do conteúdo, problemas e questões que podem ser organizados, representados e adaptados para os diversos interesses e habilidades dos alunos, e, em seguida, apresentados para o ensino.

Dentro da categoria de conhecimento pedagógico de conteúdo, incluo, os tópicos mais comumente ensinados na área, as formas mais úteis de representação dessas idéias, as analogias, ilustrações, exemplificações, explicações e demonstrações mais poderosas -resumindo, são as formas de representação e formulação do conteúdo que o torna compreensível para os outros. Uma vez que não há formas únicas de representação mais poderosas, o professor deve ter em mãos um verdadeiro arsenal de formas alternativas de representações, algumas das quais oriundas da pesquisa, enquanto outras se originam na sabedoria da prática. (...) também inclui uma compreensão do que facilita ou dificulta a aprendizagem de tópicos específicos: as concepções e equívocos que os alunos de diferentes idades e origens trazem consigo para aprender os tópicos e lições mais frequentemente ensinadas. (SHULMAN, 1986, p. 9, tradução nossa).

Como conceito, o Conhecimento Pedagógico do Conteúdo, com seu foco em representações e concepções/equívocos, ampliou ideias sobre como o conhecimento pode ser importante para o ensino, sugerindo que não é só o conhecimento do conteúdo, por um lado, e conhecimento de pedagogia, por outro lado, mas também uma espécie de amálgama de conhecimento do conteúdo e pedagogia que é fulcral para o conhecimento necessário para o ensino.

O Conhecimento Curricular constitui uma categoria que representa todos os programas concebidos para ensino de certos tópicos em dado nível, a variedade de material didático disponível etc. Assim como um médico preparado sabe exatamente qual medicamento prescrever para combater um determinado mal, o professor precisa saber qual o momento certo, para usar a ferramenta certa. Este conhecimento é

(...) representado por toda a gama de programas concebidos para o ensino de temas e tópicos específicos em um determinado nível, a variedade de materiais didáticos disponíveis em relação a esses programas, e o conjunto de características que serve tanto para as indicações quanto para contraindicações do uso de determinado currículo ou programa de materiais em circunstâncias especiais (SHULMAN, 1986; p. 10, tradução nossa). 
Chamando a atenção para o paradigma perdido, ou a ausência virtual de pesquisas focadas diretamente sobre o conhecimento do conteúdo do professor, Shulman e seus colegas definiram uma perspectiva que destacou a natureza do conteúdo intensivo no ensino.

Com Aristóteles nós afirmamos que o derradeiro teste de compreensão reside na habilidade de transformar conhecimento em ensino. Quem sabe, faz. Quem compreende, ensina. (SHULMAN, 1986, p. 14, tradução nossa).

\subsection{Conhecimento Matemático Para O Ensino}

Déborah L. Ball e seus colaboradores desenvolveram uma teoria baseada na prática, do que chamaram de Conhecimento Matemático para o Ensino (BALL, THAMES, PHELPS, 2008), construída sobre a noção de Conhecimento Pedagógico de Conteúdo de Shulman (1986). Os autores constataram que ainda havia a necessidade de mais desenvolvimento teórico, clarificação analítica e testes empíricos para as ideais propostas originalmente por Shulman em 1986. O trabalho de Ball foi investigar a natureza da orientação profissional para o conhecimento de matemática para estudos em ensino de matemática, e identificar o Conhecimento Matemático para o Ensino ${ }^{4}$. Dessa forma, Conhecimento Matemático para o Ensino (MKT) é o conhecimento de matemática do professor que se faz necessário para executar o trabalho do ensino dessa matéria.

Por "ensino", queremos dizer tudo o que os professores devem fazer para apoiar a aprendizagem dos seus alunos. Evidentemente, significa o trabalho interativo de lições de ensino nas salas de aula e todas as tarefas que surgem no decurso do mesmo trabalho. (BALL, THAMES, PHELPS, 2008, p. 395, tradução nossa).

Ball, Thames e Phelps (2008) realizaram estudos empíricos, através de registros de atividades docentes em escolas de educação básica nos Estados Unidos, além de entrevistas e questionários com professores, especialmente realizando análises dos problemas matemáticos que surgem no ensino. Com isso, os autores discerniram quatro subdomínios dentro das categorias de Shulman (ver Fig. 1): Conhecimento Comum do Conteúdo, Conhecimento Especializado do Conteúdo, Conhecimento do Conteúdo e dos Alunos e Conhecimento do Conteúdo e do Ensino. Os dois primeiros estariam contidos no Conhecimento (Disciplinar) do Conteúdo e os dois últimos no Conhecimento Pedagógico do Conteúdo 5 .

\footnotetext{
${ }^{4}$ Tradução nossa do original Mathematical Knowledge for Teaching (MKT).

${ }^{5}$ Tradução nossa dos originais Common Content Knowledge (CCK), Specialized Content Knowledge (SCK), Knowledge of Content and Students (KCS) e Knowledge of Content and Teaching (KCT).
} 
SUBJECT MATTER KNOWLEDGE

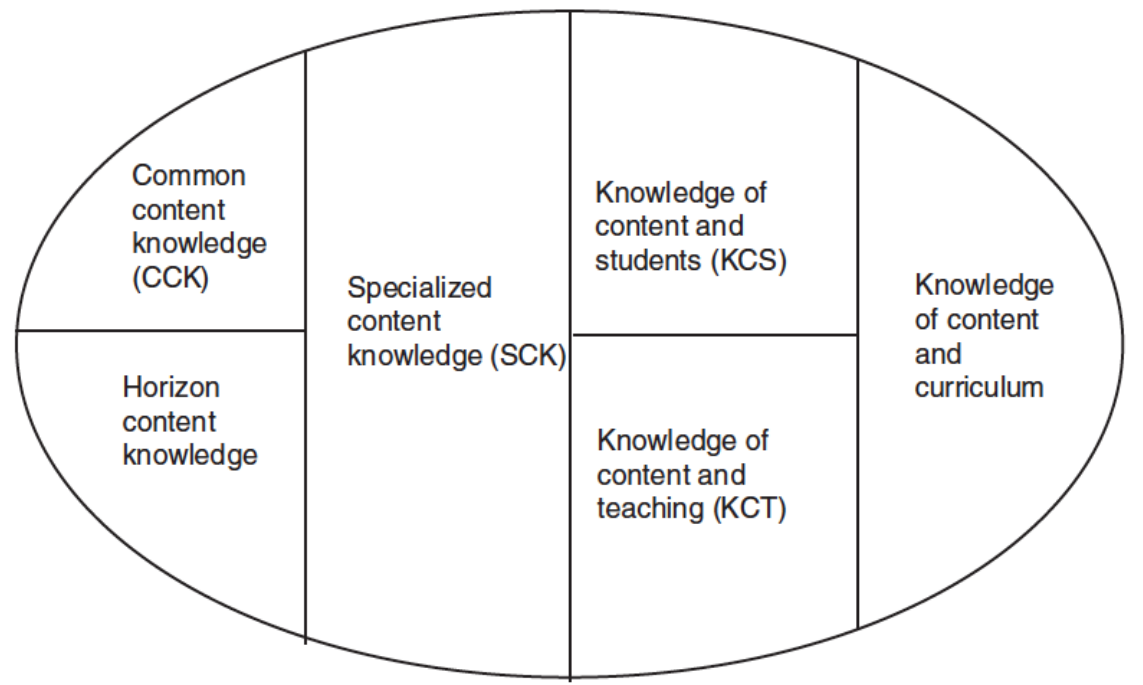

Figura 1: Domínios do Conhecimento Matemático para o Ensino Fonte: Ball, Thames, Phelps (2008, p. 403)

O Conhecimento Comum do Conteúdo seria aquele que tanto os professores de matemática como os não professores devem conhecer, enquanto que o Conhecimento Especializado é único para o ensino. No conhecimento comum do conteúdo matemático, o professor precisa saber (e bem) tudo aquilo que ele espera que seu aluno aprenda, independentemente da profissão que este aluno escolherá quando for adulto. Já o conhecimento especializado do conteúdo matemático, é único para o ensino, no sentido de que somente professores de matemática (teoricamente) necessitam dele. Muitas vezes, durante a atividade do ensino, os professores têm de fazer um tipo de trabalho matemático que outros não precisam fazer. Este trabalho envolve uma espécie de descompactação da matemática, que não se faz necessária em outras áreas. A intenção e o objetivo pedagógico, comprovam que esse tipo de conhecimento é bem mais do que uma sólida compreensão do conteúdo matemático.

Para ajudar a diferenciarmos o conhecimento comum, do conhecimento especializado, tomemos como exemplo o tópico Frações. Em nosso entendimento, o conhecimento comum de frações teria a ver com: Saber operar com frações; saber representar frações; saber resolver problemas de frações etc, enquanto que o conhecimento especializado de frações, já seria mais alinhado com: Saber formular problemas envolvendo frações; saber diferentes formas de operar e representar frações; compreender de que modo frações estão relacionadas e implicadas em outros tópicos matemáticos etc.

O terceiro é o Conhecimento do Conteúdo e dos Alunos, que é a intersecção entre o conhecimento do conteúdo e os conhecimentos acerca dos alunos, antecipando o que eles 
provavelmente irão pensar, corrigindo, intervindo e dando autonomia aos mesmos. Ao escolher um exemplo, os professores necessitam prever o que os estudantes vão achar interessante e motivador. Quando atribuir uma tarefa, os professores precisam antever o que são suscetíveis de os alunos fazerem e se eles vão achar que é fácil ou difícil. Ou seja, o conhecimento do conteúdo e alunos é um amálgama, envolvendo uma ideia particular ou procedimento matemático e a familiaridade com o que os alunos muitas vezes pensam ou realizam suas tarefas.

Em outras palavras, reconhecer uma resposta errada é o conhecimento do conteúdo comum (CCK), enquanto que avaliar a natureza de um erro, especialmente um erro desconhecido, normalmente requer agilidade no pensamento sobre números, atenção aos padrões e pensamento flexível sobre o significado de uma forma que são distintos do conhecimento de conteúdo especializado (SCK). Em contraste, a familiaridade com os erros comuns e decidir qual dos vários erros os alunos são mais propensos a cometer são exemplos de conhecimento do conteúdo e dos alunos (KCS). (BALL, THAMES, PHELPS, 2008, p. 401, tradução nossa).

O Conhecimento do Conteúdo e do Ensino é a intersecção entre matemática e ensino, diferenciando tarefas/problemas introdutórios de tarefas/problemas avançados, mensurando qual atividade é mais fácil ou mais difícil em termos gerais etc. Os professores sequenciam o conteúdo específico para as aulas. Este domínio do conhecimento, mostra-se como algo que precisa iniciar seu desenvolvimento já na formação inicial, mas que depende da prática e da experiência para amadurecer e florescer.

São os docentes que escolhem quais exemplos são melhores para começar e quais exemplos devem ser usados para levar os alunos a um conhecimento mais profundo do conteúdo. Em nossa concepção, se retomarmos ao exemplo do tópico de frações na educação básica, o Conhecimento do Conteúdo e dos Alunos convergiria para saber onde os alunos terão mais dificuldade na hora de aprender frações; antever as estratégias dos alunos na hora de somar frações com denominadores diferentes; saber analisar como e porque os alunos erraram ou acertaram cálculos envolvendo frações etc; já o conhecimento do conteúdo e do ensino, teria mais a ver com saber diferenciar e utilizar os tipos de frações adequados para a série que está lecionando; saber escolher o momento certo para abordar certos subtópicos (como a passagem da soma de frações de mesmo denominador, para a soma de frações com denominadores diferentes); escolher as frações mais simples para introduzir o conteúdo e frações mais complexas para aprofundamentos; etc.

Ball, Thames e Phelps (2008) pontuam, ainda, que, seguindo ideias de trabalhos posteriores a Shulman $(1986 ; 1987)$, colocaram o Conhecimento Curricular dentro do 
Conhecimento Pedagógico de Conteúdo, chamando-o de Conhecimento do Conteúdo e do Currículo. Além disso, discerniram ainda o que chamaram de Conhecimento do Conteúdo no Horizonte $(\mathrm{HCK})^{6}$. O conhecimento do horizonte seria uma "consciência de como temas matemáticos estão relacionados sobre a extensão da matemática incluídos no currículo" (p. 403).

Eles citam o exemplo de que professores da primeira série podem precisar saber como a matemática que ensinam está relacionada com o que os alunos irão aprender na terceira série, para serem capazes de definir a base matemática para o que virá depois. Também inclui uma visão útil em perceber ligações entre as ideias matemáticas que aparecerão posteriormente. Cientes de que seus resultados não são definitivos e inequívocos, os autores concluem afirmando que as categorias por eles propostas continuarão a precisar de refinamento e revisão.

Nesta perspectiva, Fernández e Figueiras (2014) refinaram o Conhecimento do Horizonte (HCK), entendendo que ele não teria uma posição na estrutura proposta por Ball, mas que permeia e atua sobre o KCT, KCS e SCK, chamados conhecimentos em ação, moldando-os durante a prática docente. Além disso, ele divide-se em conexões entre diferentes séries (temporal), diferentes representações de um mesmo conceito (intraconceitual) e entre conceitos diferentes (interconceitual).

\section{O Ensino De Análise Combinatória}

Optamos neste estudo por explorar o ensino de Análise Combinatória, um ramo importante da matemática escolar (ADLER, 2000). Tal ramo interage com outras teorias matemáticas (ROA, NAVARRO-PELAYO, 2001), levando a estratégias de resolução de problemas e fornecendo resultados, além de lidar geralmente com problemas concretos. A resolução de problemas pode estimular o desenvolvimento do raciocínio combinatório, imprescindível para que o aluno não acabe tomando para si a Combinatória como simplesmente o estudo dos arranjos, combinações e permutações. Esses tipos de problemas são particularmente úteis quando se aprende e ensina matemática.

Os problemas combinatórios e as técnicas para sua resolução tiveram e têm profundas implicações no desenvolvimento de outras áreas da matemática, como a probabilidade, a teoria dos números, a teoria dos autômatos e inteligência artificial, investigação operativa, geometria e topologia combinatórias. (ROA, NAVARRO-PELAYO, 2001, p.1).

\footnotetext{
${ }^{6}$ Original em Inglês: Horizon Content Knowledge (HCK).
} 
De acordo com Moreira, Alves e Magina (2013), seus muitos anos de experiência em sala de aula da Educação Básica têm mostrado que o método de ensino de professores que lecionam combinatória está pautada no paradigma Exposição-Exemplo-Exercício de maneira que:

(...) o estudante não é levado a questionar o contexto nem as implicações que cada problema tem na sua realidade. Dessa forma (...) não podemos negar que nossos estudantes possuem dificuldades na resolução de problemas combinatórios, e um dos motivos podemos dizer que vem da forma como os professores abordam esses conteúdos. (MOREIRA, ALVES, MAGINA, 2013, p. 4).

Klein (2010) defende que professores de matemática devem olhar para a Matemática Escolar de um ponto de vista superior, "de cima". Mesmo sendo de uma época muito anterior a Shulman (1986), Klein mostra ter impressões semelhantes sobre o saber necessário para o ensino, como enfatizam Rangel, Giraldo e Maculan (2014):

(...) Klein entende que o professor deve não somente ter conhecimentos específicos sobre os conceitos e as teorias que ensina, mas também saber relacioná-los e articulá-los, compreender sua natureza científica e sua evolução histórica, de forma a desenvolver uma visão ampla o suficiente para situá-los no panorama da Matemática como ciência. (RANGEL; GIRALDO; MACULAN, 2014, p. 2).

Klein (2010) argumenta que o professor precisa saber mais do que o que vai ensinar aos seus alunos. Mas, trazendo para os dias de hoje, em que se constituiria este a mais que o professor de matemática precisa saber acerca de combinatória em relação àquilo que exporá para (e explorará com) os seus alunos? Seguindo a ideia de relacionar e articular os conteúdos da matemática escolar com a matemática enquanto ciência, poderíamos pensar em subtópicos específicos que não figuram nos currículos do ensino médio regular: Como o Princípio das Casas dos Pombos, Princípio de Inclusão e Exclusão, Funções Geradoras, etc. Mas, principalmente, devemos pensar sobre aspectos pedagógicos e didáticos, tais como: De que maneira enunciar o Princípio Multiplicativo para os alunos? Em que momento podemos introduzir fórmulas que resolvem determinados tipos de problemas (como Combinações)? Que contextos e situações podem ser explorados mais a fundo nos problemas propostos aos alunos? Estes questionamentos convergem para a ideia de Conhecimento Pedagógico de Conteúdo (SHULMAN, 1986) e para os bastantes subdomínios do Conhecimento Matemático para o Ensino (BALL, THEMES, PHELPS, 2008). Refletir sobre questões como estas é um trabalho extremamente complexo e sutil, e mobiliza saberes múltiplos do professor e serão o foco do nosso trabalho. 


\section{Aspectos Metodológicos}

Ancorados em uma abordagem qualitativa de pesquisa (LÜDKE, ANDRÉ, 1986), tomamos como inspiração metodológica os estudos de Biza, Nardi e Zachariades (2007), que utilizaram cenários de investigação em uma seleção de mestrado, com vistas a avaliar o Conhecimento Pedagógico do Conteúdo (SHULMAN, 1986). Na seleção, é apresentada uma questão sobre inequação modular com resoluções fictícias de alunos, as quais deveriam ser corrigidas e comentadas pelos candidatos.

\section{Em geral, consideramos essas tarefas como oferecendo oportunidades para preparar os professores para entrarem na sala de aula com uma habilidade aprimorada para a prática reflexiva (...). Essas oportunidades podem ser na forma de oficinas nas quais os professores se envolvem e refletem/discutem suas respostas e as de outros para essas tarefas; (...) vemos esse tipo de tarefa como parte de um ambiente preparatório que levanta e desenvolve a consciência do professor (...). (BIZA, NARDI, ZACHARIADES, 2007, p. 309, tradução nossa).}

O motivo principal da escolha dessa base foi propiciar um ambiente de reflexão sobre saberes dos professores e sobre a sua prática docente, que simulasse possíveis situações reais vividas pelos professores. Acreditamos que esse tipo de discussão possibilita que os professores aprendam e (re)construam ideias pré-estabelecidas sobre determinado conteúdo da Matemática, que neste caso, é a análise combinatória (BORBA, 2010).

Fontes e Fontes (2007) sublinham a importância de se elaborar problemas fictícios baseados em realidades encontradas no cotidiano, isto é, que façam sentido para os alunos, permitindo que o professor não fique refém do livro didático que, de modo geral, apresenta os problemas de forma artificial. O problema que utilizamos em nossa atividade foi uma adaptação do problema dos diferentes caminhos (ANDREESCU, FENG, 2013; SILVA, 2013), no caso particular onde $x=6$ e $y=4)$. Enviamos o referido problema, através de uma lista de transmissão do Whatsapp, para vinte e seis professores de matemática do Ensino Médio, de escolas privadas ou públicas. Somente treze responderam à solicitação (que detalharemos a seguir) e, de acordo com a riqueza e especificidade das respostas, selecionamos quatro delas para aqui exibir e discutir, à luz dos pressupostos teóricos que balizam nosso estudo. O comando do problema enviado aos professores foi o seguinte:

Uma cidade tem forma retangular, e sua malha de ruas é composta por 7 linhas paralelas sentido norte-sul e 5 linhas paralelas para o leste-oeste, conforme ilustra a figura abaixo. De quantas maneiras um carro pode chegar ao canto nordeste (B) 
se ele começa o trajeto no canto sudoeste (A) e viaja apenas nas direções leste e norte?

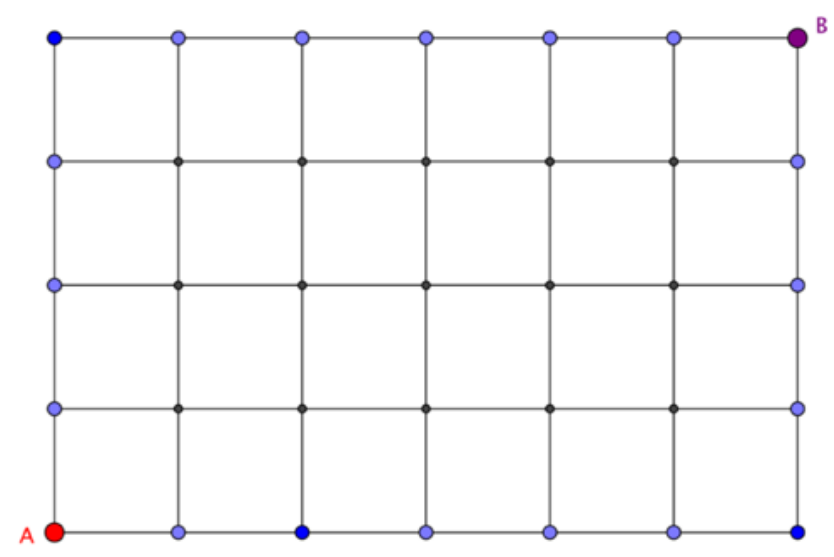

Figura 2: Malha da Cidade Fonte: Autores

Suponha que você tenha encaminhado este problema como uma tarefa para alunos de uma turma de ensino médio na qual você lecione. Após dar o visto nas soluções de cada aluno, você decide expor uma solução possível no quadro. Responda esta mensagem nos mostrando qual seria essa solução para o problema, descrevendo de que modo você explicaria cada passo para os seus alunos.

Se um de seus alunos tivesse resolvido (obtendo a resposta correta) associando o problema a uma combinação simples, e aplicando a fórmula da mesma, qual seria seu feedback a esse aluno? Você acharia importante mostrar que combinações simples e permutações com repetições (no caso de dois objetos repetidos) são equivalentes (matematicamente)?

Este problema foi adaptado e apresentado por Silva (2017), inspirado em um problema muito semelhante trazido por Andreescu e Feng (2013). Este problema, ou seus variantes, é bastante recorrente em muitos livros didáticos de matemática do ensino médio. A ideia de Silva (2017) foi

(...) mostrar alguns modos de interpretar e resolver tal problema, bem como explorar algumas possibilidades para a sua utilização em sala de aula, buscando fomentar maneiras de enriquecer a atividade do ensino e mobilizar o conhecimento do professor (tanto nos aspectos conceituais do conteúdo, quanto nos aspectos didáticos e pedagógicos). (SILVA, 2017, p. 16).

A seguir apresentamos as respostas coletadas pelo Whatsapp e discutimos sobre os aspectos do Conhecimento Matemático para o Ensino que emergiram das respostas, mostrando 
quão rico e complexo é o trabalho do professor no conteúdo em questão.

\section{Apresentação E Análise Dos Dados}

Utilizamos os nomes fictícios Alberto, Beatriz, Carla e Denis, para nos referirmos aos quatro professores de matemática do Ensino Médio citados acima, e exibiremos e analisaremos suas respectivas respostas. Nossa escolha por tais professores foi baseada na diversidade de suas resoluções, de modo que as respostas dos demais professores muito se assemelhavam com a de pelo menos um desses que destacamos para analisar. Algumas delas, convergiram para as diferentes soluções e estratégias apontadas por Silva (2017).

Cabe ressaltar que os modos de resolução foram diversos, e os professores apresentaram as soluções de maneira discursiva (digitando a solução em mensagem de texto ou tirando e enviando fotos das resoluções) ou por meio de vídeo (utilizando o geoplano e explicando oralmente sua solução).

Os professores Alberto, Beatriz e Carla, utilizaram diferentes estratégias de resolução, mas em todas elas utilizaram as tradicionais fórmulas de combinatória somente ao final da resolução. Eles demonstraram possuir um excelente domínio do Conhecimento Comum do Conteúdo (BALL, THAMES, PHELPS, 2008), ao acertar a resposta do problema, diferentemente do professor Denis, que apresentou uma solução incorreta para o mesmo.

Eu usaria o $\mathrm{PFC}^{7}$. Da cidade $\mathrm{A}$ à cidade $\mathrm{B}$ temos duas possibilidades, $\mathrm{L}$ e N. Só que para ir de A a B temos 6 etapas para o trajeto. Então para cada etapa, temos duas possibilidades, logo $2 \times 2 \times 2 \times 2 \times 2 \times 2=64$ maneiras de sair de A e chegar em B. (Prof. Denis).

Apesar de os acertos ou erros, em si, não serem os objetos de nossa atenção e discussão, mas sim os saberes considerados, mobilizados ou produzidos por cada professor, a resolução do professor Denis nos chamou muita atenção. Ela coaduna com uma possível dificuldade de estudantes do ensino médio, discutida por Silva (2017), que defende que "precisamos ser cautelosos ao dar um feedback ao aluno que faz esse raciocínio: é importante valorizar a ideia e mostrar onde está o erro que ele não percebeu!" (p. 17). Isto nos leva a pensar que, de alguma maneira, ele se sente inseguro e tem alguma dificuldade no Conhecimento Comum e, consequentemente, no Conhecimento Especializado desse conteúdo, apesar de ser um tema presente na grade curricular do Ensino Médio (onde o referido professor atua).

Percebemos ainda evidências do Conhecimento do Conteúdo e do Ensino (BALL,

${ }^{7} \mathrm{PFC}=$ Princípio Fundamental da Contagem. 
THAMES, PHELPS, 2008), quando a professora Beatriz utilizou a estratégia de permutação com repetição, mas sem utilizar a fórmula, construindo o raciocínio a partir do princípio multiplicativo, desenhando diferentes caminhos na própria malha quadriculada (Fig. 3), e também quando o professor Alberto mostra um raciocínio introdutório, antes da aplicação da fórmula. O Conhecimento Curricular (SHULMAN, 1986) também aparece, quando cada um escolheu o melhor recurso (desenho na malha feito por Beatriz, vídeo enviado por Carla e os "anagramas" de Alberto) e o Conhecimento Especializado de Conteúdo, ao escolher as melhores analogias e exemplificações para atingir o seu objetivo.

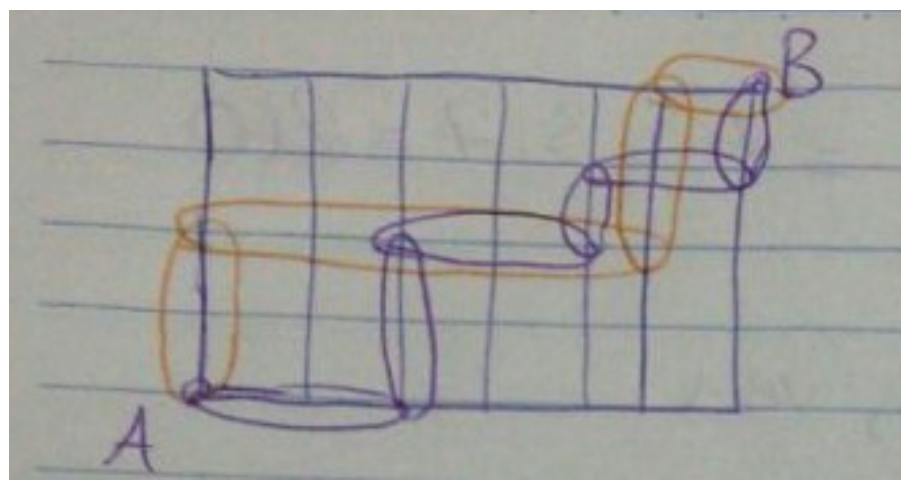

Figura 3: Ilustração dos diferentes caminhos pela professora Beatriz Fonte: Lista de Transmissão

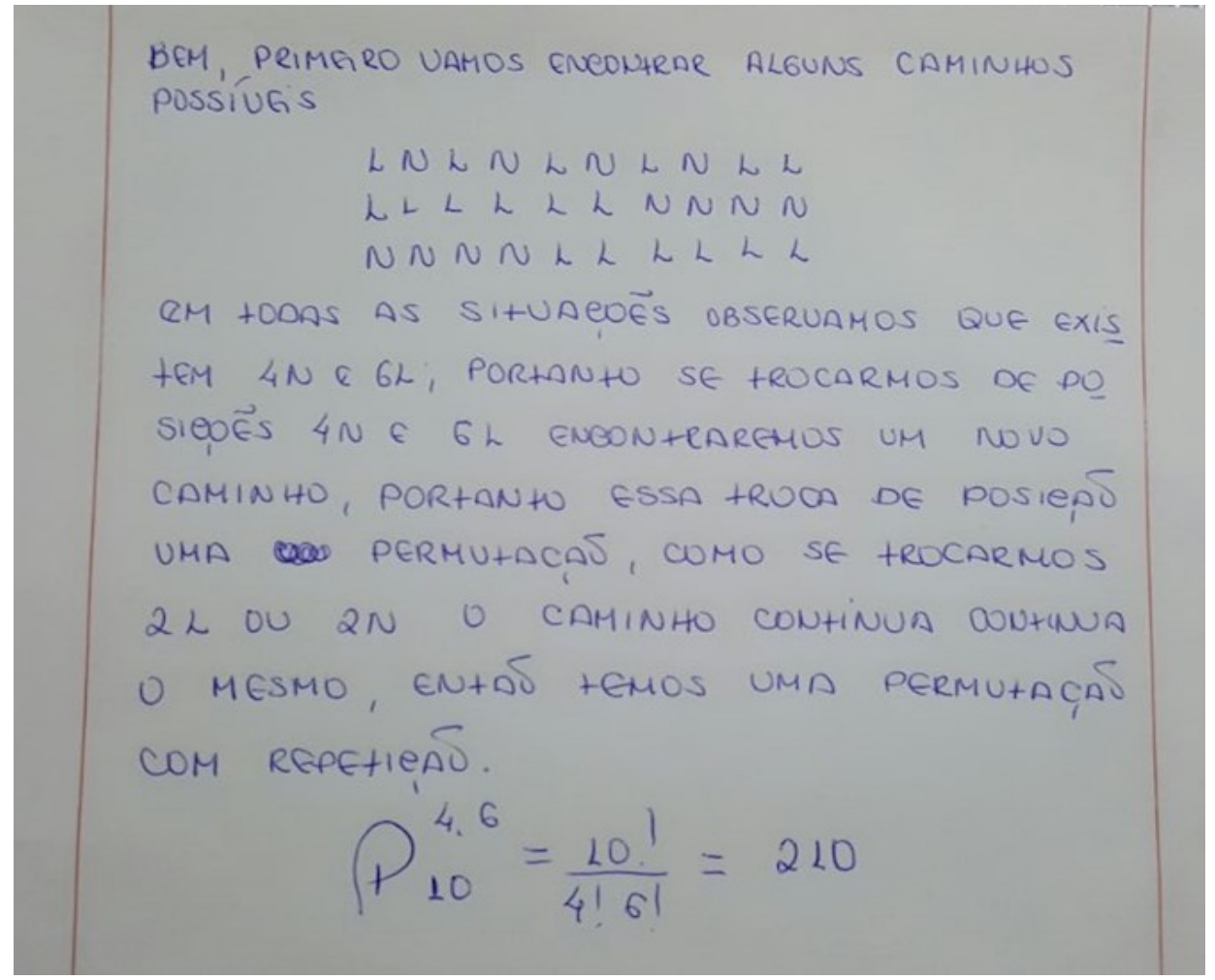

Figura 4: Solução apresentada pelo professor Alberto Fonte: Lista de Transmissão 


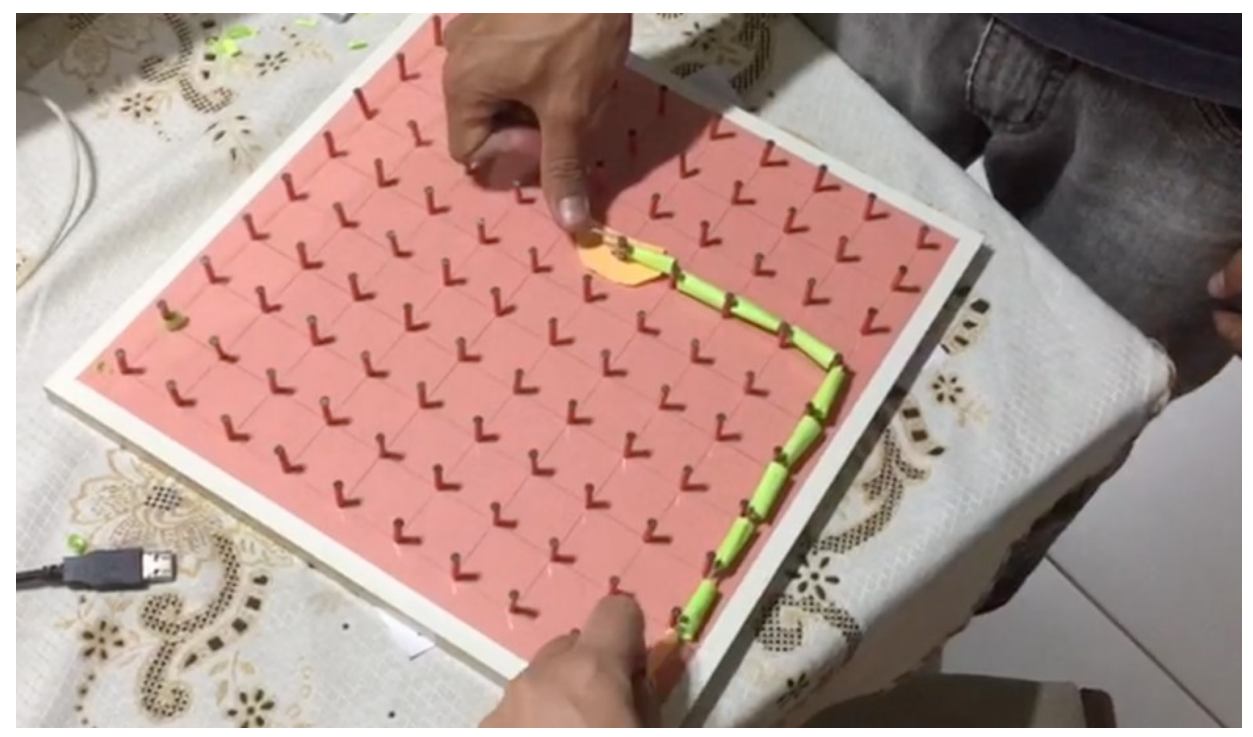

Figura 5: Solução apresentada pela professora Carla Fonte: Lista de Transmissão

Com base na nossa análise dos dados, acreditamos que é possível inferir que um saber que permeou a resolução de cada um dos quatro professores foi o Conhecimento do Conteúdo e dos Alunos (BALL, THAMES, PHELPS, 2008), pois as estratégias utilizadas por todos (até mesmo o professor Denis) levaram em consideração o possível entendimento e possíveis confusões que poderiam ser cometidas pelos seus alunos. Alberto, por exemplo, iniciou a resolução construindo uma analogia entre os movimentos e as letras, L para leste e N para norte, a fim de que os alunos compreendessem a permutação dos elementos (letras) e por acreditar que seria de melhor entendimento para os mesmos. Assim, adaptou a situação para um problema de permutação com elementos repetidos (L se repete 6 vezes e $\mathrm{N}, 4$ vezes) e apenas ao final utilizou a fórmula (Fig. 4). Em relação à segunda pergunta, Alberto relatou que comentaria sobre a combinação simples, mostrando compreender e dispor de diferentes estratégias de resolução, o que converge para o Conhecimento Especializado de Conteúdo.

Outro fato que fomenta a presença do Conhecimento do Conteúdo e dos Alunos, e também do Conhecimento Curricular, foi a preocupação da professora Carla em mostrar de maneira dinâmica, em vídeo, os possíveis caminhos para se chegar ao ponto B (Fig. 5). Na ocasião, a mesma lançou mão o uso do geoplano, utilizando os pregos como "cruzamentos das ruas" e os espaços entre os pregos, como "as ruas". A partir dessa adaptação do geoplano, e explicando oralmente o que estava fazendo, Carla justificou de modo muito didático, porque cada caminho diferente se configurava como uma combinação simples de 6 elementos agrupados de 4 em 4 .

Cabe destacar que, usando estratégias, recursos e ferramentas conceituais diferentes 
(respectivamente, Permutações com Repetições e Combinações Simples), os professores Alberto e Carla confirmaram as ideias de Shulman (1986), quando o mesmo afirma que "não há formas únicas de representação mais poderosas, o professor deve ter em mãos um verdadeiro arsenal de formas alternativas de representações". (p. 9).

Destacamos também o fato de os professores se preocuparem com a ilustração do problema e não só com a abstração. Apesar de o professor Denis não ter apresentado nenhuma ilustração, ele relata que "É óbvio que seria interessante fazer uma ilustração no quadro para mostrar o raciocínio e não ficar apenas na retórica".

Outros saberes emergiram das falas dos professores. Em particular, o professor Alberto, em nossa leitura, evidencia alguns deles. Agregando especificidades ao problema, o professor utilizou a criatividade ao dizer que "colocaria uma farmácia em um ponto da malha", readaptando o problema para passar nessa farmácia antes de chegar ao ponto B. Além disso, Alberto afirma que "não usaria combinação com repetição, porque não se vê isso no Ensino Médio". Essa fala tem a ver com o conhecimento sobre o currículo, ao reconhecer que em nenhuma série os alunos teriam contato com essa faceta das combinações. Entretanto, temos visto alguns livros didáticos e algumas propostas curriculares no Brasil e no mundo, que trabalham este subtópico.

\section{Considerações Finais}

A partir de uma lista de transmissão em um aplicativo de mensagens instantâneas, podemos observar aspectos dos saberes categorizados por Shulman (1986) e refinados por Ball, Thames e Phelps (2008), dentro do problema dos diferentes caminhos (ANDREESCU, FENG, 2013; SILVA, 2017). O discurso dos professores evidenciou uma riqueza de saberes, e, mesmo no professor que não chegou na resposta correta (210), foi possível identificar alguns dos aspectos e especificidades do Conhecimento Matemático para o Ensino. Uma solução totalmente inesperada para nós foi a da professora Carla, em vídeo, mostrando que a academia pode aprender muito com os professores, pois no "palco" da sala de aula teorizam, aprendem e inovam. Acreditamos que as formações de professores devem ser construídas dentro da profissão (NOVOA, 2009), a partir da partilha de saberes, estudos de casos concretos, e maior colaboração entre os pares.

Sabemos que a simulação é somente uma representação da realidade da sala de aula, porém, nos aproxima da mesma e permite afirmar que o ensino de análise combinatória pode 
ser mais ricamente explorado na formação de professores (BORBA, 2010). Cabe ressaltar que não buscamos nessa atividade categorizar e separar os saberes em "caixinhas", mas ilustrar as complexidades e especificidades do conhecimento do professor de matemática, especialmente olhando para a sua formação continuada.

Ademais, dentro da perspectiva proposta, os professores tiveram a oportunidade de refletir sobre alguns aspectos de seu Conhecimento Matemático para o Ensino com vistas a contribuir para sua prática profissional em sala de aula. Na esteira do trabalho de Shulman (1986), temos a ambição de contribuir para que o Saber (disciplinar) do Conteúdo (Combinatória) destes profissionais se articule com seu saber pedagógico do conteúdo, culminando num eficaz desenvolvimento profissional e em um norteamento para a constante reflexão sobre a sua própria prática docente.

A ferramenta metodológica utilizada para levantamento dos dados, a lista de transmissão do Whatsapp, se mostrou extremamente eficaz, dentro do que propomos levantar e analisar. Não detalhamos muito certas especificidades, detalhamentos e até contratempos no uso desta ferramenta, por não ser este o foco de nosso estudo. Devido ao relativo sucesso de nossa empreitada, julgamos ser um terreno fértil para pesquisas futuras, e até como desdobramento direto deste trabalho, analisar e avaliar o uso do whatsapp como instrumento de levantamento/produção de dados qualitativos para a pesquisa no campo educacional.

\section{Referências}

ADLER, J. Conceptualizing Resources as a Theme for Teacher Education. Journal of Mathematics Teacher Education, v. 3, n. 3, p. 205-224, 2000.

ALMEIDA, A. L. Ensinando e Aprendendo Análise Combinatória com Ênfase na Comunicação Matemática: Um Estudo de Caso com o ${ }^{\circ}$ Ano do Ensino Médio. 2010. 166 f. Dissertação (Mestrado em Educação Matemática) - UFOP, Ouro Preto, 2010.

ANDREESCU, T.; FENG, Z. A Path to Combinatorics for Undergraduates: Counting Strategies. Springer Science \& Business Media, 2013.

BALL, D. L.; THAMES, M. H. T.; PHELPS, G. Content Knowledge for Teaching, What Makes It Special? Journal of Teacher Education p. 389-407, 2008.

BIZA, I.; NARDI, E.; ZACHARIADES, T. Using Tasks to Explore Teacher Knowledge in Situation-Specific Contexts. Journal of Mathematics Teacher Education, v. 10, n. 4-6, p. 301-309, 2007.

BORBA, R. O raciocínio combinatório na educação básica. Anais do X Encontro Nacional de Educação Matemática. Salvador/BA, 2010.

EVEN, R.; BALL, D. The professional education and development of teachers of mathematics The 15th ICMI Study. 2009, New York, NY: Springer. 
FERNÁNDEZ, S.; FIGUEIRAS, L. Horizon Content Knowledge: Shaping MKT for a Continuous Mathematical Education. REDIMAT, v. 3, n. 1, p. 7-29, 2014.

FONTES, M.; FONTES, D. Análise combinatória: uma abordagem através de contexto. Anais do IX Encontro Nacional de Educação Matemática - ENEM, Belo Horizonte, 2007.

GERALDI, C. M. G; MESSIAS, M. G. M.; GUERRA, M. D. S. Refletindo com Zeichner: um encontro orientado por preocupações políticas, teóricas e epistemológicas. Cartografias do trabalho docente, v. 3, p. 237-276, 1998.

KLEIN, F. Matemática elementar de um ponto de vista superior-Volume 1-primeira parte: Aritmética. Tradução de Tiago Pedro e Suzana Metello de Nápoles. Lisboa: Sociedade Portuguesa de Matemática, 2010.

LÜDKE, M.; ANDRÉ, M. E. D. A. Pesquisa em Educação: Abordagens Qualitativas. São Paulo: EPU, 1986.

MOREIRA, F. M. B.; ALVES, S. M.; MAGINA, S. M. P. A Análise Combinatória na Formação de Professores que Ensinam Matemática: um Estudo Diagnóstico. In: Encontro Brasileiro de Estudantes de pós-graduação em Educação Matemática, 2013, Vitória-ES. Programação e Caderno de Resumos, 2013.

RANGEL, L. G.; GIRALDO, V.; MACULAN, N. Matemática Elementar e Saber Pedagógico de Conteúdo - Estabelecendo Relações. Professor de Matemática Online - SBM. No. 1, v.2. ISSN 2319-023, 2014.

ROA, R.; NAVARRO-PELAYO, V. Razonamiento Combinatorio e Implicaciones para la Enseñanza de la Probabilidad. Jornadas europeas de estadística. Illas Baleares, 10 e 11 de outubro de 2001 .

SHULMAN, L. S. Those Who Understand: Knowledge Growth in Teaching. Stanford University. 15, p. 4-14, 1986.

SHULMAN, L. S. Knowledge and Teaching: Foundations of the New Reform. Harvard educational review, v. 57, n. 1, p. 1-23, 1987.

SILVA, E. O Problema dos Diferentes Caminhos. Revista do Professor de Matemática, v. 94, p. 1619, 2017.

ZEICHNER, K. Novos Caminhos para o Practicum: Uma Perspectiva para os Anos 90. Os professores e sua formação. 2. Ed. Portugal: Dom Quixote, 1995. 